\title{
Lactating dairy cows managed for second and greater artificial insemination services with the Short-Resynch or Day 25 Resynch program had similar reproductive performance
}

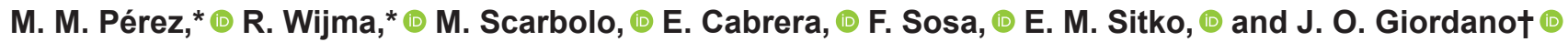 \\ Department of Animal Science, Cornell University, Ithaca, NY 14853
}

\begin{abstract}
The objective of this randomized controlled experiment was to evaluate reproductive performance and reproductive physiological outcomes of lactating Holstein cows managed for second and greater artificial insemination (AI) services with the Short-Resynch or Day 25 Resynch program. Cows from 2 commercial farms were randomly assigned after first service to the Short-Resynch (SR; $\mathrm{n}=870$ ) or Day 25 Resynch $(\mathrm{D} 25 \mathrm{R} ; \mathrm{n}=917)$ program in which they remained until $210 \mathrm{~d}$ after first service or left the herd. Cows in D25R received $\mathrm{GnRH} 25 \pm 3 \mathrm{~d}$ after $\mathrm{AI}$, whereas cows in SR did not. Cows not reinseminated at detected estrus (AIE) by $32 \pm 3$ d after AI underwent nonpregnancy diagnosis (NPD) through transrectal ultrasonography (TUS). Nonpregnant cows from both treatments with a corpus luteum $(\mathrm{CL}) \geq 15 \mathrm{~mm}$ and an ovarian follicle $\geq 10 \mathrm{~mm}$ (hereafter, CL cows) received $2 \mathrm{PGF}_{2 \alpha}$ treatments $24 \mathrm{~h}$ apart, GnRH $32 \mathrm{~h}$ after the second $\mathrm{PGF}_{2 \alpha}$, and timed AI 16 to $18 \mathrm{~h}$ later. Cows that did not meet the criteria to be included in the CL group (NoCL cows) received a modified Ovsynch protocol with progesterone (P4) supplementation [P4-Ovsynch; GnRH and controlled internal drug-release device (CIDR) in, $7 \mathrm{~d}$ later CIDR removal and $\mathrm{PGF}_{2 \alpha}, 24$ h later $\mathrm{PGF}_{2 \alpha}$, $32 \mathrm{~h}$ later $\mathrm{GnRH}$, and 16 to $18 \mathrm{~h}$ later timed $\mathrm{AI}$. In a subgroup of cows, blood samples were collected and TUS conducted at each treatment to evaluate ovarian responses to resynchronization. Binary data were analyzed with logistic regression, continuous data by ANOVA, and time-to-event data by Cox's proportional hazard regression. A greater proportion (mean; 95\% $\mathrm{CI}$ ) of cows were AIE before NPD in the SR (60.5\%; $57.0-63.8 ; \mathrm{n}=3,416)$ than the D25R $(50.1 \%$; 46.5-53.7; $\mathrm{n}=3,177)$ treatment, whereas pregnancy per $\mathrm{AI}(\mathrm{P} /$ $\mathrm{AI})$ at $32 \mathrm{~d}$ for AIE services before NPD was greater
\end{abstract}

Received March 28, 2020.

Accepted July 1, 2020.

*These authors contributed equally to this work.

†Corresponding author: jog25@cornell.edu for the D25R $(41.3 \% ; 38.8-43.8 ; \mathrm{n}=1,560)$ than the SR $(37.6 \% ; 35.5-39.8 ; \mathrm{n}=1,961)$ treatment. At NPD, a greater proportion of cows in the D25R (84.3\%; 82.2-86.2) than the SR (77.0\%; 74.4-79.4) treatment were considered CL cows. Pregnancy per AI at $32 \mathrm{~d}$ was greater for the D25R than the SR treatment for all timed AI services (D25R $=43.0 \% ; 40.2-45.9$ vs. $\mathrm{SR}=36.8 \%$; 33.8-39.8) and for CL cows (D25R = $42.8 \% ; 39.7-45.9$ vs. $\mathrm{SR}=33.8 \% ; 30.6-37.2)$ but $\operatorname{did}$ not differ for NoCL cows (D25R $=39.4 \%$; 32.1-47.3 vs. $\mathrm{SR}=44.0 \% ; 36.8-51.4)$. The hazard ratio for time to pregnancy $(1.03 ; 0.93-1.14)$ and the proportion of cows not pregnant at the end of the observation period $(\mathrm{D} 25 \mathrm{R}=5.9 \% ; 4.4-7.8$ vs. $\mathrm{SR}=6.7 \% ; 5.0-8.7)$ did not differ between SR and D25R treatments. The GnRH treatment $25 \mathrm{~d}$ after AI resulted in more cows with $\mathrm{P} 4$ $>1 \mathrm{ng} / \mathrm{mL}(\mathrm{D} 25 \mathrm{R}=80.5 \% ; 75.3-84.9$ vs. $\mathrm{SR}=63.6 \%$; 57.3-69.4) and smaller follicle diameter at NPD $32 \pm 3$ $\mathrm{d}$ after AI for D25R $(16.2 \pm 0.4 \mathrm{~mm})$ than for SR (17.5 $\pm 0.4 \mathrm{~mm}$ ); however, it did not affect follicle diameter and luteal regression risk (CL cows only) before TAI. We concluded that the use of reproductive management programs including SR and D25R for CL cows and the P4-Ovsynch protocol for NoCL cows resulted in similar hazard of pregnancy and proportion of nonpregnant cows for up to $210 \mathrm{~d}$ after first service.

Key words: resynchronization, dairy cow, timed AI, reproductive performance

\section{INTRODUCTION}

Implementation of effective strategies to reinseminate lactating dairy cows is critical for minimizing days to pregnancy and reducing the proportion of nonpregnant cows at the end of lactation (Pursley et al., 1997; Tenhagen et al., 2004; Wijma et al., 2018). Many alternatives are available to submit dairy cows for second and greater AI services; however, strategies to manage reinsemination typically consist of a combination of $\mathrm{AI}$ at detected estrus (AIE) and timed AI (TAI) after resynchronization of ovulation. The latter is usually accomplished with the Ovsynch protocol or 
its variants for cows not AIE by the time of nonpregnancy diagnosis (NPD; Fricke et al., 2003; Bilby et al., 2013; Bruno et al., 2014). Recently, reproductive management programs including resynchronization tailored to cows with certain ovarian structures at NPD have been developed and evaluated (Bartolome et al., 2005; Giordano et al., 2015; Wijma et al., 2017). These programs attempt to reduce days to pregnancy by targeting subgroups of cows based on their expected response to resynchronization, which in turn optimizes the reinsemination interval, pregnancy per AI $(\mathbf{P} / \mathbf{A I})$, or both (Bartolome et al., 2005; Wijma et al., 2017, 2018). Moreover, certain aspects of management such as the ratio of cows reinseminated by AIE versus TAI, the number of interventions required before reinsemination, and reproductive program implementation cost can also be optimized.

A targeted reproductive management program for second and greater AI services combines the ShortResynch (SR) protocol for cows with a corpus luteum $(\mathbf{C L}) \geq 15 \mathrm{~mm}$ and a follicle $\geq 10 \mathrm{~mm}$ (hereafter, CL cows) with a modified Ovsynch protocol with progesterone (P4) supplementation (P4-Ovsynch) for cows that do not meet the criteria to be included in the CL group (hereafter, NoCL cows; Wijma et al., 2017). The benefits of this program depend on the ovarian status of cows at NPD. For CL cows, the SR protocol is aimed at minimizing the reinsemination interval while not disrupting the pattern of spontaneous expression of estrus before NPD. For NoCL cows, the P4-Ovsynch protocol is expected to increase the fertility of TAI services, because these cows would likely have low $\mathrm{P} / \mathrm{AI}$ if they received the same protocol as CL cows or a typical Ovsynch-like protocol with no P4 supplementation (Wijma et al., 2018). In addition, a potential practical benefit of this program is the lack of an initial $\mathrm{GnRH}$ treatment. Unlike resynchronization programs that include GnRH to induce ovulation and a new follicular wave before NPD (Fricke et al., 2003; Sterry et al., 2006), using the SR protocol for CL cows could reduce the reinsemination interval for most nonpregnant cows (i.e., CL cows) avoiding treatment of pregnant cows with GnRH before NPD.

A potential caveat of removing the $\mathrm{GnRH}$ treatment before induction of luteolysis for CL cows that receive $\mathrm{SR}$ is reduced $\mathrm{P} / \mathrm{AI}$ for TAI services because of reduced control of the follicular wave dynamics and hormonal milieu before TAI (Wijma et al., 2017). Indeed, reduced $\mathrm{P} / \mathrm{AI}$ was observed for CL cows resynchronized with $\mathrm{SR}$ in an experiment that compared the reinsemination dynamics and P/AI of TAI services for lactating dairy cows managed with the SR or Day 25-Resynch (D25R, which includes $\mathrm{GnRH}$ treatment $25 \pm 3 \mathrm{~d}$ after $\mathrm{AI}$ ) protocols (Wijma et al., 2017). In contrast to the det- rimental effect of SR on fertility of CL cows, removing the GnRH before NPD favored reinsemination of cows at detected estrus, which generated enough pregnancies to compensate for the fewer pregnancies generated by TAI. Unfortunately, the design of the experiment reported in Wijma et al. (2017) precluded evaluating the effect of treatments on time to pregnancy and proportion of cows nonpregnant at the end of lactation because cows were reassigned to treatments after each AI service. Thus, additional research is necessary to determine the effect on time to pregnancy and total proportion of cows pregnant at the end of lactation when using the SR or D25R protocol for CL cows at NPD.

Therefore, for this experiment, we hypothesized that a greater proportion of reinseminations at detected estrus for the program including SR would compensate for the reduced $\mathrm{P} / \mathrm{AI}$ of TAI services for CL cows, resulting in hazard of pregnancy and time to pregnancy similar to that of cows managed with the program including the D25R protocol. A secondary hypothesis was that inclusion of GnRH treatment $25 \pm 3 \mathrm{~d}$ after $\mathrm{AI}$ in the D25R program would affect ovarian responses during resynchronization. Specifically, more cows would have a CL present and reduced follicle size at NPD compared with cows in the SR program. Therefore, the objectives of this experiment were to evaluate reproductive performance and reproductive physiological outcomes of lactating Holstein cows when using the SR or D25R protocol for CL cows and the P4-Ovsynch protocol for NoCL cows.

\section{MATERIALS AND METHODS}

This experiment was conducted from November 2016 to March 2018 in 2 commercial dairy farms located in Tompkins and Cayuga counties in New York State. All procedures were approved by the Animal Care and Use Committee of the College of Agriculture and Life Sciences of Cornell University.

\section{Cows and General Management}

During the experiment, farm A milked $\sim 2,100$ cows (range 1,884 to 2,302) thrice daily at approximately 8-h intervals and had average milk yield per cow of $\sim 40 \mathrm{~kg} / \mathrm{d}$ (range 38 to $44 \mathrm{~kg} / \mathrm{d}$ ). Cows were housed in 6-row freestall barns and fed a TMR once daily with ad libitum access to feed and water. Diets were formulated to meet or exceed the nutrient requirements of lactating dairy cows producing $45 \mathrm{~kg} / \mathrm{d}$ of milk with $3.8 \%$ fat and $3.1 \%$ true protein, as indicated by the Cornell Net Carbohydrate and Protein System (Van Amburgh et al., 2015). All cows received recombinant bovine so- 
matotropin (rbST; $500 \mathrm{mg}$ of Sometribove zinc; Posilac, Elanco Animal Health, Indianapolis, IN) at 14-d intervals beginning at $60 \pm 3$ DIM until dry off. On December 31, 2017, rbST treatments were discontinued. Thus, $93.1 \%$ of the cows received rbST treatments for the entire duration of the experiment, $2.0 \%$ received treatments until treatments were discontinued, and $4.9 \%$ of the cows did not receive treatment. For the first service, cows were submitted to the Presynch-Ovsynch protocol as described in Moreira et al. (2001), except that the GnRH before TAI was given $56 \mathrm{~h}$ after the PGF treatment for induction of luteolysis. Cows detected in estrus after the first and second $\mathrm{PGF}_{2 \alpha}$ treatments of the protocol administered at $53 \pm 3$ and $67 \pm 3$ DIM were immediately inseminated. Cows not detected in estrus within $11 \mathrm{~d}$ of the second $\mathrm{PGF}_{2 \alpha}$ received the Ovsynch portion of the protocol and TAI at $88 \pm 3$ DIM. Approximately $81 \%$ of the cows received the first service at detected estrus, whereas the remaining cows received TAI.

During the experiment, farm B milked $\sim 1,300$ cows (range 1,090 to 1,443) with an average milk yield of $\sim 42 \mathrm{~kg} / \mathrm{d}$ (range 36 to $45 \mathrm{~kg} / \mathrm{d}$ ). Cows were housed in freestall barns with 6 or 8 rows of stalls and were fed a TMR once a day with ad libitum access to feed and water. Diets were formulated to meet or exceed the nutrient requirements of lactating dairy cows producing $45 \mathrm{~kg} / \mathrm{d}$ with $3.8 \%$ fat and $3.1 \%$ true protein, as indicated by the Cornell Net Carbohydrate and Protein System (Van Amburgh et al., 2015). Cows were milked 4 times daily at approximately 6 -h intervals. All cows received recombinant bovine somatotropin at 10 - or 11-d intervals beginning at $110 \pm 3$ DIM in primiparous cows and $80 \pm 3$ DIM in multiparous cows until dry off. On December 31, 2017, rbST treatments were discontinued. Thus, $93.5 \%$ of the cows received rbST treatments for the entire duration of the experiment, $1.3 \%$ received treatments until treatments were discontinued, and $5.2 \%$ of the cows did not receive treatment. Primiparous cows received first service through TAI at $81 \pm 3$ DIM and multiparous cows at $67 \pm 3$ DIM after synchronization of ovulation with the Double-Ovsynch protocol (Souza et al., 2008). Cow numbers and milk production data were retrieved using the ECON $\backslash$ ID command from DairyComp305 (ValleyAg Software, Tulare, CA).

\section{Treatment Allocation and Implementation of Experimental Treatments}

Every week during the period of allocation of cows to the experiment, a list of eligible cows was retrieved from the dairy herd management software (DairyComp305).
Cows were eligible for the experiment if they were in the milking herd, were not coded as do not breed, and had received their first AI service the previous week. Eligible cows were blocked by parity (primiparous vs. multiparous), stratified by DIM, and, within parity group, randomly assigned by research personnel to the SR $(\mathrm{n}=870)$ or D25R $(\mathrm{n}=917)$ treatments. Treatments were reproductive management strategies for second and greater AI services in which cows remained enrolled until the next calving if pregnant, coded as do not breed, or until they exited the herd due to sale or death. Sixteen cows, which were eligible for the experiment in more than one lactation, were randomized to the experimental treatments in each lactation. Enrollment into the experiment spanned more than 12 mo to have inseminations during the cold and warm seasons of the year. The treatment code assigned to cows was used by custom-built commands in the dairy herd management software to automatically generate lists of cows for hormonal treatments, TAI, and pregnancy testing on specific days of the week. The code was not included in action lists to ensure that research and farm personnel were blind to treatments.

All cows were eligible for AIE any time after enrollment in the experiment. If detected in estrus, cows were immediately inseminated. In farm A, detection of estrus was conducted once daily through visual observation and tail paint removal, whereas in farm $\mathrm{B}$ detection of estrus was conducted by an automated system for detection of estrus based on physical activity monitoring by leg-mounted sensors (Afi-ActII, Afikim, Kibbutz Afikim, Israel). Cows were inseminated once daily after the first morning milking session.

At $25 \pm 3$ d after AI, cows in D25R received a $\mathrm{GnRH}$ treatment $(86 \mu \mathrm{g}$ of gonadorelin diacetate tetrahydrate, Fertagyl, Merck Animal Health, Summit, NJ), whereas cows in SR received no GnRH treatment. Seven days later at $32 \pm 3 \mathrm{~d}$ after $\mathrm{AI}$, cows from both treatments not reinseminated at detected estrus underwent NPD through TUS (Ibex Pro, Ibex, Loveland, CO). A cow was considered pregnant when at least one CL was present on one of the ovaries, the amount and appearance of uterine fluid was consistent with the expected stage of gestation, and at least one embryo of the expected size and shape for the stage of gestation was visualized. Pregnant cows received no further treatment. For cows diagnosed nonpregnant, TUS of both ovaries was conducted to evaluate the presence and record the size of all CL and the largest 2 follicles. Size of the CL and follicles was estimated using the ultrasound machine's grid lines (squares of 10 by $10 \mathrm{~mm}$ ). All TUS examinations were conducted by veterinarians. In farm A, TUS was conducted by 2 of the co-authors (M.P. and R.W.) 
and the practicing veterinarian, whereas in farm B it was conducted by the same 2 co-authors (M.P. and R.W.).

After NPD, cows from both treatments were treated equally. Cows with at least one $\mathrm{CL} \geq 15 \mathrm{~mm}$ and at least one ovarian follicle $\geq 10 \mathrm{~mm}$ in diameter (CL cows) received a $\mathrm{PGF}_{2 \alpha}$ treatment (500 $\mu \mathrm{g}$ of cloprostenol sodium, Estrumate, Merck Animal Health), a second $\mathrm{PGF}_{2 \alpha} 24 \mathrm{~h}$ later, GnRH $32 \mathrm{~h}$ after the second $\mathrm{PGF}_{2 \alpha}$, and TAI 16 to $18 \mathrm{~h}$ later (Figure 1). Cows that did not meet the criteria to be included in the CL group (NoCL cows) received a modified Ovsynch protocol (i.e., 2 $\mathrm{PGF}_{2 \alpha}$ treatments) with $\mathrm{P} 4$ supplementation through an intravaginal P4-releasing device (CIDR; $1.38 \mathrm{~g}$ of progesterone, Eazi-Breed CIDR, Zoetis, Florham Park, NJ) from the time of the first GnRH to the first $\mathrm{PGF}_{2 \alpha}$ treatment of the protocol $(\mathrm{GnRH}$ and CIDR inserted, 7 d later CIDR removal and $\mathrm{PGF}_{2 \alpha}, 24 \mathrm{~h}$ later $\mathrm{PGF}_{2 \alpha}$, $32 \mathrm{~h}$ later GnRH, and 16 to $18 \mathrm{~h}$ later TAI; Figure 1). Hereafter, the resynchronization of ovulation protocol for NoCL cows will be referred to as P4-Ovsynch. Every time a cow was diagnosed nonpregnant, it was classified as CL or NoCL and received the respective resynchronization of ovulation protocols based on ovarian status (i.e., for CL or NoCL cows). Therefore, cows in the SR and D25-Resynch treatments that received multiple TAI services until the end of the 210-d at-risk period may have received different resynchronization of ovulation treatments (i.e., treatment for CL or NoCL cows) depending on the ovarian structures present at NPD.
Reconfirmation of pregnancy was performed $63 \pm 3$ d after AI by TUS in both farms. Pregnancy loss was recorded when a cow pregnant at the initial examination was not pregnant at the time of reconfirmation. Pregnancy loss was also recorded for cows AIE after the first pregnancy confirmation. Cows found not pregnant at a pregnancy reconfirmation were immediately enrolled in the Ovsynch protocol (GnRH, $7 \mathrm{~d}$ later $\mathrm{PGF}_{2 \alpha}, 56 \mathrm{~h}$ later $\mathrm{GnRH}$, and 16 to $18 \mathrm{~h}$ later TAI). Cows that were TAI following the Ovsynch protocol after a pregnancy loss and failed to conceive were AIE or received resynchronization treatments at NPD based on their respective experimental treatments (i.e., SR or D25R) and ovarian structures present at the next NPD.

All inseminations were conducted using conventional semen from a total of 237 bulls (73 farm A and 164 farm B) distributed randomly by treatment and type of insemination (i.e., AI at detected estrus and TAI). In farm $\mathrm{A}$, the number of inseminations per sire (mean $\pm \mathrm{SD}$ ) was $53.4 \pm 47$ with a range of 1 to 177 . In farm $\mathrm{B}$, the number of inseminations per sire was $13.7 \pm 15$ with a range of 1 to 110 . Inseminations were conducted by a total of 16 in-house technicians (9 in farm $\mathrm{A}$ and 7 in farm B) who were blind to treatments at the time of insemination. In farm A, 5 technicians conducted $89.5 \%$ of the inseminations (range 324 to 1,039 ) and 4 technicians conducted $10.5 \%$ of the inseminations (range 2 to 197). In farm B, 2 technicians conducted $74.9 \%$ of the inseminations (range 652 to 1,028) and 5 technicians conducted $25.1 \%$ of the inseminations (range 18 to 261 ).

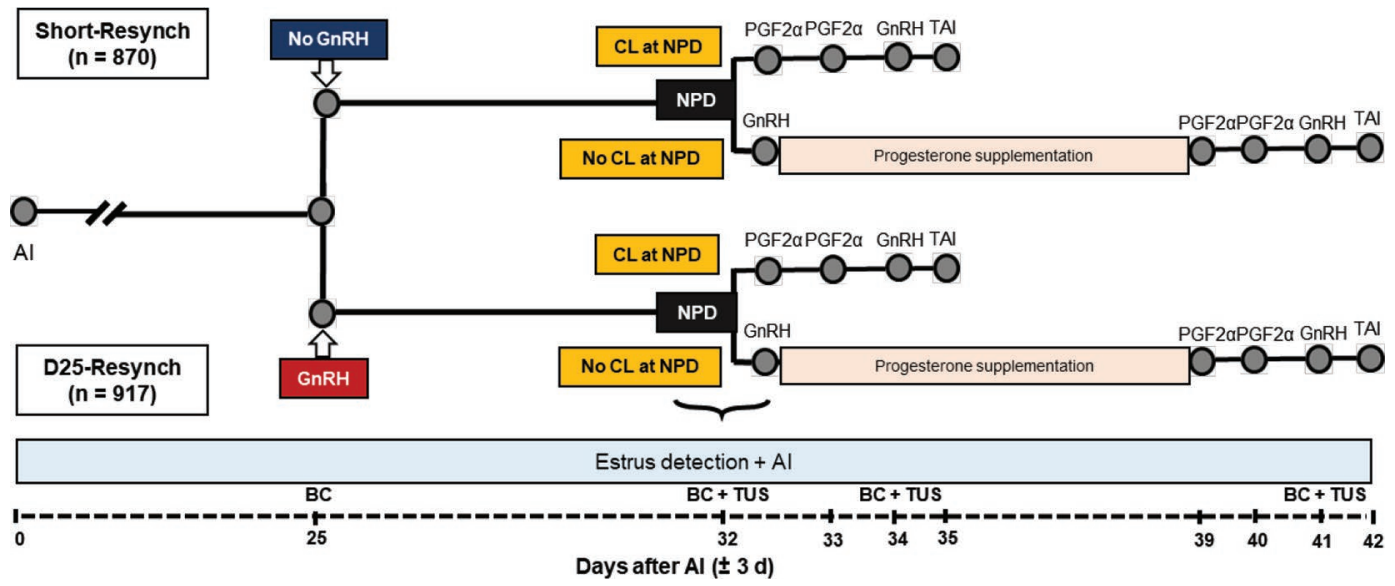

Figure 1. Graphical representation of experimental procedures. At $25 \pm 3 \mathrm{~d}$ after AI, cows in Day 25-Resynch received a GnRH treatment, whereas cows in Short-Resynch did not receive GnRH. At $32 \pm 3 \mathrm{~d}$ after AI, cows from both treatments not reinseminated at detected estrus underwent nonpregnancy diagnosis (NPD) through transrectal ultrasonography (TUS). After NPD, cows from both treatments with at least one corpus luteum (CL) $\geq 15 \mathrm{~mm}$ and at least one ovarian follicle $\geq 10 \mathrm{~mm}$ in diameter (CL cows) received $\mathrm{PGF}_{2 \alpha}$, a second $\mathrm{PGF} \mathrm{F}_{2 \alpha} 24 \mathrm{~h}$ later, GnRH $32 \mathrm{~h}$ after the second $\mathrm{PGF}_{2 \alpha}$, and timed AI (TAI) 16 to $18 \mathrm{~h}$ later. Cows that did not meet the criteria (NoCL cows) received a modified Ovsynch protocol (i.e., $2 \mathrm{PGF}_{2 \alpha}$ treatments) with progesterone supplementation through an intravaginal progesterone releasing device from the time of the first $\mathrm{GnRH}$ to the first $\mathrm{PGF}_{2 \alpha}$ treatment of the protocol. $\mathrm{BC}=$ blood collection. 


\section{Evaluation of Ovarian Responses}

In a subgroup of cows from farm B, blood samples were collected for subsequent determination of circulating concentrations of P4 (farm A did not allow sample collection). Samples were collected at $25 \pm 3 \mathrm{~d}$ after AI from 212 and 196 cows in the D25R and SR treatments, respectively. Thereafter, samples were collected at 32 \pm 3 and $34 \pm 3 \mathrm{~d}$ after $\mathrm{AI}$ for CL cows (D25R $=237$ and $\mathrm{SR}=191)$ and at $32 \pm 3$ and $41 \pm 3 \mathrm{~d}$ after $\mathrm{AI}$ for NoCL cows $(\mathrm{D} 25 \mathrm{R}=45$ and $\mathrm{SR}=70)$. Blood $(\sim 8$ to $9 \mathrm{~mL}$ ) was collected through puncture of the coccygeal blood vessels using evacuated tubes containing sodium heparin (BD Vacutainer, Franklin Lakes, NJ). Samples were placed in a cooler with ice packs within $<5 \mathrm{~min}$ of collection and then transported to the laboratory within $<3 \mathrm{~h}$ of collection. Samples were centrifuged for $20 \mathrm{~min}$ at $1,700 \times g$ at $4^{\circ} \mathrm{C}$. Plasma was collected into Eppendorf tubes and stored at $-20^{\circ} \mathrm{C}$ until assays were performed.

In addition, TUS of the ovaries was conducted to determine the presence of and estimate the size of all CL and the 2 largest ovarian follicles at $32 \pm 3$ and 34 $\pm 3 \mathrm{~d}$ after $\mathrm{AI}$ in CL cows $(\mathrm{D} 25 \mathrm{R}=237$ and $\mathrm{SR}=191)$ and $32 \pm 3$ and $41 \pm 3 \mathrm{~d}$ after AI in NoCL cows (D25R $=44$ and $\mathrm{SR}=69)$. The size of ovarian structures was estimated as described for the time of NPD.

\section{Determination of Circulating Progesterone Concentrations}

Circulating concentrations of $\mathrm{P} 4$ were determined in duplicate using a commercially available solid-phase, no-extraction RIA (ImmuChem Coated Tube, MP Biomedicals, Costa Mesa, CA). To assess the precision of the assays, control samples with high $(4.7 \mathrm{ng} / \mathrm{mL})$ and low $(0.2 \mathrm{ng} / \mathrm{mL})$ concentrations of $\mathrm{P} 4$ were included at the beginning and end of each assay ( $\mathrm{n}=13$ assays). Average detection limit for the P4 assay was $0.15 \mathrm{ng} /$ $\mathrm{mL}$. Average intraassay coefficient of variation $(\mathbf{C V})$ for the high-concentration sample was $6.1 \%$ whereas the interassay CV was $15.1 \%$. For the low-concentration sample, the average intraassay CV was $13.3 \%$ whereas the interassay CV was $21.1 \%$.

The cutoff for circulating concentration of $\mathrm{P} 4$ used to classify cows into high and low P4 groups was $1 \mathrm{ng} /$ $\mathrm{mL}$. Luteal regression was defined as a reduction in circulating $\mathrm{P} 4$ from $\geq 1 \mathrm{ng} / \mathrm{mL}$ at the time of induction of luteal regression to $<0.5 \mathrm{ng} / \mathrm{mL}$ at the time of the GnRH treatment before TAI. Luteal regression risk was only calculated for CL cows because blood samples were not collected at the time of induction of luteal regression for NoCL cows.

\section{Statistical Analysis}

This experiment was conducted as a complete randomized block design using parity (primiparous vs. multiparous) as the blocking factor. The sample size calculation was conducted to estimate the number of cows per treatment required to test the hypothesis that the hazard ratio for time to pregnancy for the D25R and SR treatments would be $\leq 1.15$. In a previous experiment investigating programs for second and greater AI, we observed that a hazard ratio of up to 1.15 for time to pregnancy after first service did not generate a significant difference in the proportion of cows pregnant by the end of the at-risk period (Giordano et al., 2015). In addition, the equivalence margin selected (i.e., $\delta=0.15$ ) assumed that a reduction of up to $15 \%$ in the rate of pregnancy creation per unit of time for the SR treatment would be acceptable. According to the estimation conducted using the sample size calculation option for survival time of WinPepi version 11.51 (Abramson, 2011), a total of 896 cows per treatment were required when the expected probability of survival (i.e., proportion of cows not pregnant) at the end of the experimental period is $10 \%$, the probability of type I error rate is $5 \%$, and the probability of type II error rate is $20 \%$.

Binary outcomes (i.e., proportion of CL and NoCL cows, P/AI, pregnancy loss, proportion of cows AIE or TAI, proportion of cows not pregnant $210 \mathrm{~d}$ after the first service, proportion of cows with high or low P4 concentration, and luteal regression risk) were analyzed using logistic regression with the GLIMMIX procedure of SAS (version 9.4, SAS Institute Inc., Cary, NC) fitting a binomial distribution. Separate models were built depending on the type of outcome analyzed but for most outcomes, models were run for all cows combined, CL cows only, and NoCL cows only. Treatment and parity (primiparous vs. multiparous) were included as fixed effects, whereas cow nested within farm was included as random effect because some cows contributed with data from more than one insemination. Season of insemination [warm (June, July, and August) vs. cold (September to May)] was offered to initial models for $\mathrm{P} / \mathrm{AI}$ and pregnancy loss. Treatment and parity were forced in all models, whereas season was removed from final models if $P>0.10$.

Continuous outcomes (interval between reinseminations, circulating concentrations of $\mathrm{P} 4$, and follicle size) were analyzed by ANOVA using the MIXED procedure of SAS, including treatment and parity as fixed effects. Cows were included as a random effect because some cows contributed with data from more than one insemination. Follicle size was analyzed with separate models 
to account for the presence of putative follicular cysts defined as fluid-filled cavities $>25 \mathrm{~mm}$ in diameter and follicle-like appearance at the ultrasonography evaluation. One set of models was run including putative cyst in the calculation of largest follicle size (i.e., putative cyst was considered largest follicle present), whereas another set of models excluded putative cysts from the calculation of largest follicle size (i.e., putative cysts were ignored so the largest noncystic follicle was used for size calculation). As for binary outcomes, separate models were built depending on the type of outcome analyzed but for most outcomes, models were run for all cows combined, CL cows only, and NoCL cows only. Assumptions of normality of residuals and homoscedasticity for linear models were tested by evaluating normal probability plots (Q-Q plot) and plotting residuals versus predicted values. Data transformations and nonparametric models were used for outcome variables that violated assumptions. Data for circulating concentrations of $\mathrm{P} 4$ at $25 \pm 3$ and $32 \pm 3 \mathrm{~d}$ after AI were square root-transformed. Analysis of circulating concentrations of $\mathrm{P} 4$ at the time of GnRH before TAI was conducted by a Kruskal-Wallis test using the NPAR1WAY procedure of SAS because none of the data transformations corrected for lack of normality of the model residuals.

Cox's proportional hazards regression analysis using the PHREG procedure of SAS was used to compare time to pregnancy for up to $210 \mathrm{~d}$ after the first service. The at-risk period for pregnancy was established for individual cows to ensure that all cows were at risk for $210 \mathrm{~d}$. Thus, the first day at risk was the day after the first service for individual cows, not the average DIM for all cows. Cows no longer eligible for AI due to a farm management decision (i.e., coded as do not breed) or that left the herd due to sale or death were right censored. A pregnancy event was entered for a cow only if pregnancy was maintained until pregnancy reconfirmation. Cows with pregnancy loss before $60 \mathrm{~d}$ of gestation after conceiving to first service were included in the analysis with the $210-\mathrm{d}$ risk period initiated at the time of first service as for the rest of the cows. Treatment, parity, and milk production tercile group (calculated for farm and parity group within farm) were offered to the model as fixed effects, whereas farm was included as a random effect. Milk production groups created based on milk production projected to 305 DIM for farm A were low (primiparous $\leq 11,173$ $\mathrm{kg}$, multiparous $\leq 12,707 \mathrm{~kg}$ ); medium (primiparous 11,174 to $12,798 \mathrm{~kg}$, multiparous 12,708 to 15,073 $\mathrm{kg}$ ); and high (primiparous $\geq 12,799 \mathrm{~kg}$, multiparous $\geq 15,074 \mathrm{~kg}$ ). For farm B, milk production groups were low (primiparous $\leq 10,528 \mathrm{~kg}$, multiparous $\leq 12,176 \mathrm{~kg}$ ); medium (primiparous 10,529 to $12,117 \mathrm{~kg}$, multiparous
12,177 to $14,223 \mathrm{~kg}$ ); and high (primiparous $\geq 12,118$ $\mathrm{kg}$, multiparous $\geq 14,224 \mathrm{~kg}$ ). Milk production level was removed from the final model because $P=0.74$. Milk production tercile was also offered to the logistic regression model used to evaluate the proportion of cows nonpregnant at the end of the 210 -d at-risk period. The proportional hazard assumption for time to event data analysis was evaluated by graphical examination of the $\log [-\log$ (survival probability)] function obtained from the LIFETEST procedure of SAS. The assumption of proportional hazards was met. Kaplan-Meier survival curves were generated to illustrate the pregnancy rate after the first service using the survival analysis option of MedCalc (version 12.5.0.0; MedCalc Software bvba, Ostend, Belgium).

All proportions reported are least squares means (LSM) and their 95\% CI generated using the lsmeans statement of PROC GLIMMIX. For simplicity of presentation, some proportions are presented as arithmetical means generated using the FREQ procedure of SAS. Values for continuous outcomes are reported as $\mathrm{LSM} \pm \mathrm{SEM}$ obtained with the lsmeans statement of the MIXED procedure of SAS. The MEANS procedure of SAS was used to obtain means and standard error of the mean for values not generated from statistical models. All explanatory variables were considered significant if $P \leq 0.05$, whereas $P>0.05$ and $\leq 0.10$ was considered a tendency.

\section{RESULTS}

\section{Reinsemination Pattern and Pregnancy per Al}

A greater $(P<0.001)$ proportion of cows was reinseminated at detected estrus before NPD in the SR $(60.5 \% ; 57.0$ to $63.8 ; \mathrm{n}=3,416)$ than the D25R $(50.1 \%$; 46.5 to $53.7 ; \mathrm{n}=3,177)$ treatment. Parity $(P<0.001)$ and season $(P<0.001)$ of insemination also affected the proportion of cows AIE before NPD: more primiparous $(57.6 \% ; 54.0$ to 61.1$)$ than multiparous $(53.1 \% ; 49.5$ to $56.5)$ cows were AIE and more cows were AIE during the cold $(58.8 \%$; 55.5 to 62.0$)$ than the warm $(51.9 \%$; 47.9 to 55.8 ) season of the year. The mean interval between AI services was shorter $(P=0.001)$ for SR $(27.3 \pm 0.2 \mathrm{~d})$ than D25R $(28.2 \pm 0.2 \mathrm{~d})$. Pregnancy per AI at $32 \pm 3 \mathrm{~d}$ after AI for AIE services before NPD was greater $(P=0.03)$ for the D25R $(41.3 \% ; 38.8$ to $43.8 ; \mathrm{n}=1,560)$ than the SR $(37.6 \% ; 35.5$ to $39.8 ; \mathrm{n}=$ $1,961)$ treatment and tended to be greater $(P=0.09)$ for primiparous $(40.9 \%$; 38.4 to 43.4$)$ than for multiparous $(38.0 \% ; 35.9$ to 40.2$)$ cows. Additionally, $\mathrm{P} / \mathrm{AI}$ at $63 \pm 3 \mathrm{~d}$ after AI for AIE services before NPD tended to be greater $(P=0.10)$ for the D25R $(38.0 \% ; 35.6$ to 40.5) than the SR $(35.3 \% ; 33.2$ to 37.5$)$ treatment but 
did not differ $(P=0.13)$ for primiparous $(37.9 \% ; 35.4$ to 40.5$)$ and multiparous $(35.4 \%$; 33.3 to 37.6$)$ cows. Pregnancy loss from $32 \pm 3$ to $63 \pm 3 \mathrm{~d}$ after AI did not differ $(P=0.20)$ for D25R $(8.9 \% ; 5.9$ to 13.3$)$ and SR $(7.1 \% ; 4.6$ to 10.7$)$ or for primiparous $(7.8 \% ; 5.0$ to $11.8)$ and multiparous $(8.0 \% ; 5.3$ to 12.1$)$ cows $(P=$ $0.83)$.

At NPD, a greater $(P<0.001)$ proportion of cows in the D25R $(84.3 \% ; 82.2$ to 86.2$)$ than in the SR $(77.0 \%$; 74.4 to 79.4 ) treatment had a CL $\geq 15 \mathrm{~mm}$ and a follicle $\geq 10 \mathrm{~mm}$ and were therefore considered CL cows. All remaining cows in both treatment groups were considered NoCL cows. The proportion of CL cows at NPD did not differ $(P=0.84)$ for primiparous $(81.1 \%$; 78.4 to 83.5$)$ and multiparous $(80.7 \% ; 78.6$ to 82.7$)$ cows.

Data for evaluation of $\mathrm{P} / \mathrm{AI}$ for AI services after NPD was available for 1,422 and 1,184 AI services for the D25R and SR treatments, respectively. The number of inseminations after NPD was greater than the number of cows enrolled in the experiment because, by design, some cows were inseminated more than once during the experimental period. Out of all inseminations, $7.9 \%$ (n $=206 / 2,606$ ) were conducted at detected estrus after NPD until the day before TAI. The proportion of cows AIE from NPD to TAI was not different for the D25R and SR treatments when all cows were combined $(P=$ $0.74 ; \mathrm{D} 25 \mathrm{R}=8.1 \% ; 6.7$ to 9.7 and $\mathrm{SR}=7.7 \% ; 6.3$ to $9.5)$ or for CL $(P=0.11)$ and NoCL $(P=0.15)$ cows and was not affected by parity for any subgroup $(P>$ 0.10 ). Irrespective of treatment and CL group, overall $\mathrm{P} / \mathrm{AI}$ for cows AIE $(50.9 \% ; 44.1$ to $57.7 ; \mathrm{n}=206)$ was greater $(P=0.001)$ than for cows that received TAI $(39.3 \% ; 37.2$ to $41.3 ; \mathrm{n}=2,400)$ and was affected by parity $(P=0.05)$ because it was greater for primiparous $(47.0 \%$; 42.3 to 51.3$)$ than for multiparous $(43.1 \%$; 39.3 to 46.9$)$ cows.

Overall, $\mathrm{P} / \mathrm{AI}$ at $32 \pm 3 \mathrm{~d}$ after AI for all TAI services combined was greater $(P=0.003)$ for the D25R than the SR treatment (Table 1) and it was greater $(P=0.01)$ for primiparous $(42.5 \% ; 39.2$ to 45.9$)$ than multiparous cows (37.2\%; 34.7 to 39.9). Pregnancy per AI for TAI services for cows in the CL group was greater $(P<0.001)$ for the D25R than for the SR treatment (Table 1) and for primiparous $(40.8 \% ; 37.2$ to 44.4) than for multiparous cows (35.7\%; 33.0 to 38.6 ; $P=0.03)$. Conversely, $\mathrm{P} / \mathrm{AI}$ for TAI services for NoCL cows did not differ $(P=0.36)$ for cows in the D25R and SR treatment (Table 1), did not differ $(P=0.14)$ for primiparous $(45.6 \% ; 37.3$ to 54.0$)$ and multiparous $(38.0 \% ; 31.5$ to 44.8$)$ cows, but was greater $(P=0.04)$

Table 1. Pregnancy per AI (P/AI) and pregnancy loss for cows that received the experimental treatments

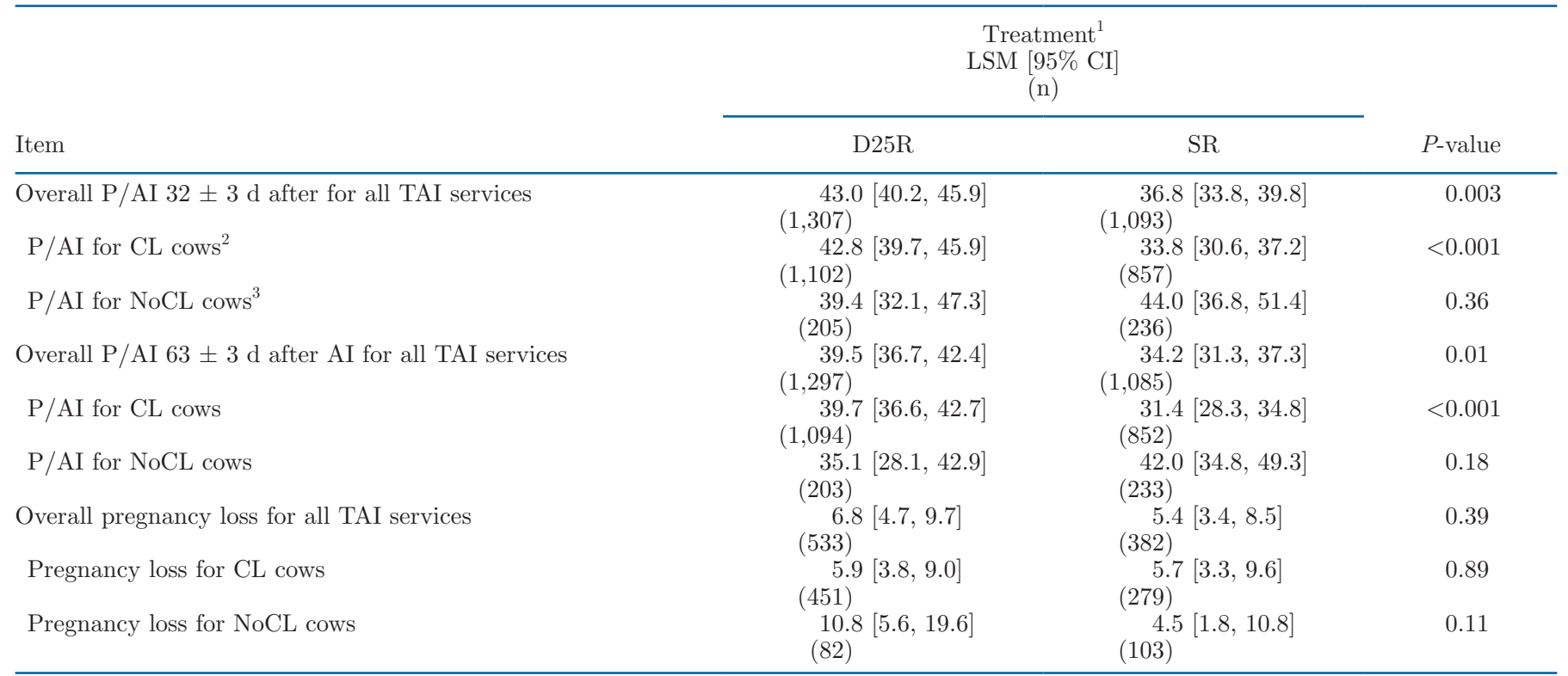

\footnotetext{
${ }^{1}$ Treatment $=$ cows enrolled in the Day 25 Resynch (D25R) program received GnRH $25 \pm 3$ d after AI, whereas cows in Short-Resynch (SR) did not receive $\mathrm{GnRH}$. Cows in both programs not reinseminated at detected estrus (AIE) until nonpregnancy diagnosis (NPD) at $32 \pm 3 \mathrm{~d}$ after AI were classified and treated according to their ovarian structures present at NPD. Cows with at least one corpus luteum (CL) $\geq 15$ mm and one ovarian follicle $\geq 10 \mathrm{~mm}$ (CL cows) received $2 \mathrm{PGF}_{2 \alpha}$ treatments $24 \mathrm{~h}$ apart, GnRH $32 \mathrm{~h}$ after the second PGF $\mathrm{P}_{2 \alpha}$, and timed AI 16 to $18 \mathrm{~h}$ later. Cows that did not meet the criteria to be included in the CL group (NoCL cows) received a modified Ovsynch protocol with progesterone (P4) supplementation (P4-Ovsynch; GnRH and CIDR in, $7 \mathrm{~d}$ later CIDR removal and $\mathrm{PGF}_{2 \alpha}, 24 \mathrm{~h}$ later $\mathrm{PGF}_{2 \alpha}, 32 \mathrm{~h}$ later GnRH, and 16 to 18 h later timed $\mathrm{AI})$.

${ }^{2}$ Cows with at least one $\mathrm{CL} \geq 15 \mathrm{~mm}$ and a follicle $\geq 10 \mathrm{~mm}$.

${ }^{3}$ Cows with no CL $\geq 15 \mathrm{~mm}$ or no follicle $\geq 10 \mathrm{~mm}$.
} 
during the cold $(47.6 \% ; 41.5$ to 53.8$)$ than the warm $(36.0 \% ; 27.7$ to 45.3$)$ season of the year.

At $63 \pm 3 \mathrm{~d}$ after $\mathrm{AI}$, overall $\mathrm{P} / \mathrm{AI}$ for all inseminations combined was greater $(P=0.01)$ for the D25R than the SR treatment (Table 1$)$ and it was greater $(P$ $=0.001)$ for primiparous cows $(40.3 \% ; 37.0$ to 43.6$)$ than for multiparous cows (33.5\%; 31.0 to 36.1). For CL cows, $\mathrm{P} / \mathrm{AI}$ was greater $(P<0.001)$ for the $\mathrm{D} 25 \mathrm{R}$ than for the SR treatment (Table 1$)$ and greater $(P<0.01)$ for primiparous (38.8\%; 35.3 to 42.5$)$ than multiparous cows $(32.2 \% ; 29.5$ to 35.0$)$. Conversely, for NoCL cows, $\mathrm{P} / \mathrm{AI}$ did not differ $(P=0.18)$ for cows in the D25R and SR treatments, but tended to be greater $(P=0.10)$ for primiparous $(42.8 \% ; 34.7$ to 51.3$)$ than multiparous $(34.3 \% ; 28.1$ to 41.1$)$ cows.

Pregnancy loss from $32 \pm 3$ to $63 \pm 3 \mathrm{~d}$ after AI was similar $(P=0.39)$ for the D25R and SR treatments (Table 1$)$ but was greater $(P=0.02)$ for multiparous $(8.7 \% ; 6.4$ to 11.8$)$ than primiparous $(4.1 \% ; 2.4$ to 7.0$)$ cows. Pregnancy loss did not differ by treatment for CL $(P=0.89)$ and NoCL cows $(P=0.11$; Table 1$)$. For CL cows, pregnancy loss was greater $(P=0.02)$ for multiparous $(9.0 \% ; 6.3$ to 12.7$)$ than primiparous cows $(3.7 \% ; 1.9$ to 7.0$)$. No differences $(P=0.47)$ between parities were observed for NoCL cows.

\section{Time to Pregnancy Outcomes}

The hazard ratio (HR) for time to pregnancy for up to $210 \mathrm{~d}$ after the first service did not differ $(P=0.60)$ for the D25R and SR treatments $(\mathrm{HR}=1.03 ; 95 \% \mathrm{CI}$ : 0.93-1.14; Figure 2) but tended to be greater $(P=$ $0.09)$ for primiparous than multiparous $(\mathrm{HR}=1.10$; 95\% CI: 0.99-1.22) cows. Median days to pregnancy were 67 (95\% CI: 60-70) and 70 (95\% CI: 63-75) d for the D25R and SR treatments, respectively. Mean days to pregnancy were $85.5 \pm 2.1$ and $87.3 \pm 2.2 \mathrm{~d}$ for D25R and SR, respectively.

The proportion of cows not pregnant (i.e., out of the cows that remained in the herd) at the end of the 210-d at-risk period $(\mathrm{D} 25 \mathrm{R}=790$ and $\mathrm{SR}=747)$ did not differ by treatment $(P=0.54 ; \mathrm{D} 25 \mathrm{R}=5.9 \% ; 4.4$ to 7.8 vs. $\mathrm{SR}=6.7 \% ; 5.0$ to 8.7$)$ or parity $(P=0.97$; primiparous $=6.2 \% ; 4.6$ to 8.4 vs multiparous $=6.2 \% ; 4.8$ to 8.1$)$ but differed by milk production group $(P=0.02$; high $=8.5 \% ; 6.5$ to 11.1 , medium $=7.5 \% ; 5.6$ to 10.0 , low $=3.8 \% ; 2.3$ to 6.1 ).

\section{Ovarian Responses}

For cows with $\mathrm{P} 4$ data available $25 \pm 3$ d after AI (n $=408$ ), mean circulating concentrations of $\mathrm{P} 4$ for all cows combined were $2.7 \pm 0.1 \mathrm{ng} / \mathrm{mL}$ and did not differ $(P=0.80)$ for the SR and D25R treatment (Table 2) or by parity $(P=0.23)$. Likewise, a similar proportion of cows had $\mathrm{P} 4>1 \mathrm{ng} / \mathrm{mL}(P=0.29)$ for the SR and D25R treatments (Table 2) and there was no effect of parity $(P=0.86)$ when all cows were included in the comparison. Conversely, when circulating concentrations of $\mathrm{P} 4$ at $25 \pm 3 \mathrm{~d}$ after AI were compared by treatment for cows that were included in the CL or NoCL group at NPD, P4 differed by treatment for cows in the CL $(P=0.01)$ and NoCL $(P<0.001)$ group (Table 2). For the NoCL group, P4 concentrations were also affected by parity $(P<0.01)$ because $\mathrm{P} 4$ concentrations were greater for primiparous $(2.5 \pm 0.4$ $\mathrm{ng} / \mathrm{mL})$ than for multiparous $(0.9 \pm 0.2 \mathrm{ng} / \mathrm{mL})$ cows. Likewise, the proportion of cows with $\mathrm{P} 4>1 \mathrm{ng} / \mathrm{mL}$ $25 \pm 3 \mathrm{~d}$ after AI differed $(P<0.01)$ by treatment for cows that were later (i.e., at NPD) in the CL group and tended to differ $(P=0.07)$ by treatment for cows in the NoCL group (Table 2). For the NoCL group, there was also a tendency $(P=0.06)$ for the effect of parity because more primiparous (53.9\%; 95\% CI 36.1 to 70.8 ) than multiparous $(26.3 \% ; 95 \%$ CI 11.6 to 49.2$)$ cows had $\mathrm{P} 4>1 \mathrm{ng} / \mathrm{mL}$.

For cows with $\mathrm{P} 4$ data available $32 \pm 3 \mathrm{~d}$ after AI (n $=543)$, mean circulating concentrations of $\mathrm{P} 4$ were 3.1 $\pm 0.1 \mathrm{ng} / \mathrm{mL}$ and tended to differ $(P=0.08)$ for SR and D25R for all cows combined (Table 2) and were not affected by parity $(P=0.99)$. The proportion of cows with $\mathrm{P} 4>1 \mathrm{ng} / \mathrm{mL}$ was greater $(P<0.001)$ for the D25R than the SR treatment (Table 2) but was not affected by parity $(P=0.69)$. When $\mathrm{P} 4$ concentrations at

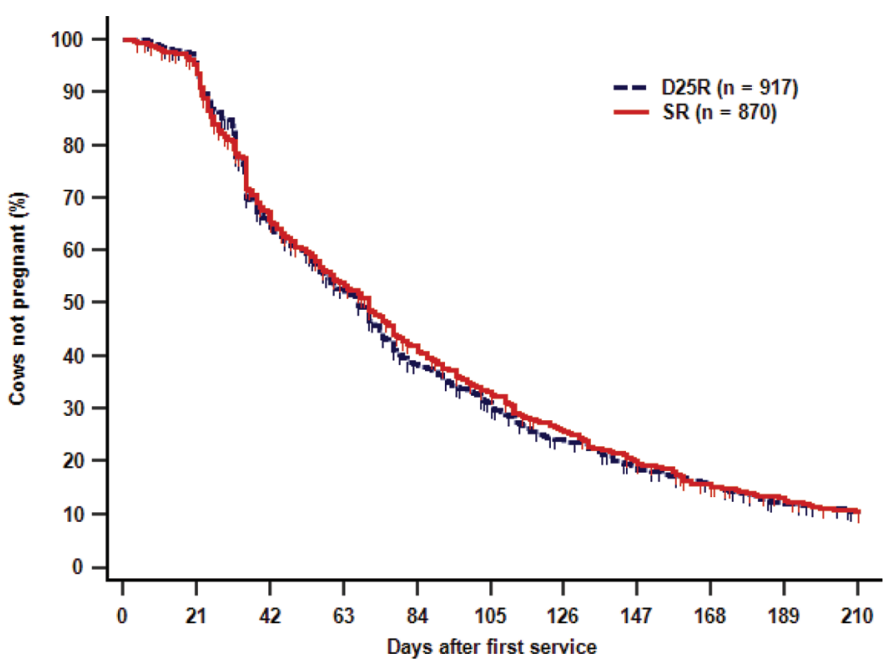

Figure 2. Kaplan-Meier survival curves for time to pregnancy for $210 \mathrm{~d}$ after the first service for cows in the Day 25 Resynch (D25R) and Short-Resynch (SR) treatments. The hazard of pregnancy did not differ ( $P=0.60$; hazard ratio $1.03,95 \% \mathrm{CI}$ : 0.93 to 1.14$)$ with median days to pregnancy of 67 (95\% CI: 60 to 70$)$ and 70 (95\% CI: 63 to 75$)$ $\mathrm{d}$ for the D25R and SR treatments, respectively. Mean days to pregnancy were $85.5 \pm 2.1$ and $87.3 \pm 2.2 \mathrm{~d}$ for D25R and SR, respectively. 
Pérez et al.: RESYNCHRONIZATION FOR LACTATING DAIRY COWS

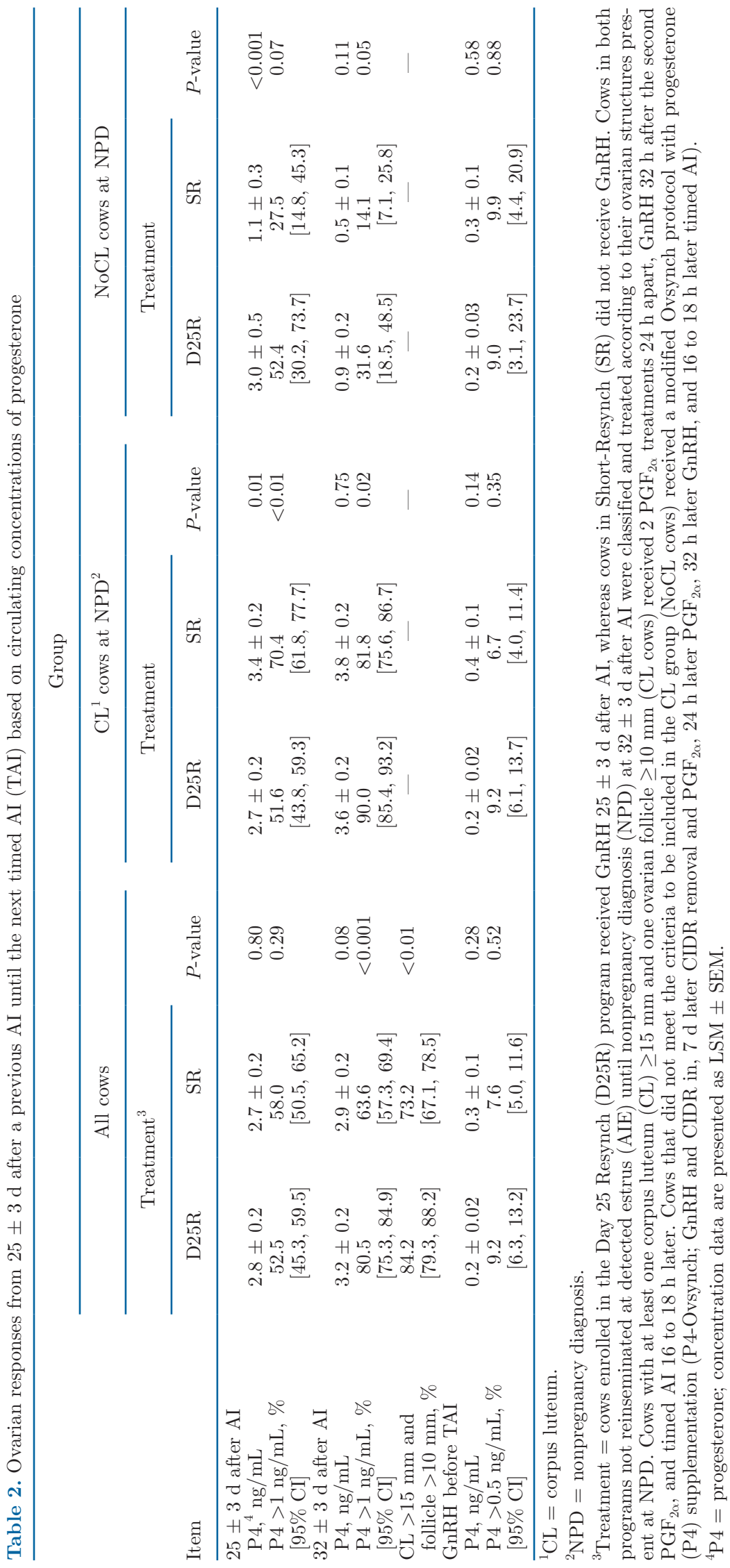


NPD were compared by treatment within the CL and NoCL group, no difference was observed for cows in the CL $(P=0.75)$ and the NoCL $(P=0.11)$ groups (Table $2)$. Conversely, the proportion of cows with $\mathrm{P} 4>1 \mathrm{ng} /$ $\mathrm{mL}$ differed by treatment for cows in the CL $(P=0.02)$ and NoCL $(P=0.05)$ groups at NPD (Table 2$)$. The proportion of cows with a CL $\geq 15 \mathrm{~mm}$ and follicle $\geq 10$ mm visualized by TUS was greater $(P<0.01)$ for the D25R (84.2\%; 79.3 to 88.2$)$ than SR $(73.2 \% ; 67.1$ to $78.5)$ treatment but similar $(P=0.28)$ for primiparous $(77.2 \% ; 71.4$ to 82.1$)$ and multiparous $(81.1 \% ; 75.8$ to 85.5) cows.

For cows with $\mathrm{P} 4$ data available at the $\mathrm{GnRH}$ before TAI ( $\mathrm{n}=543)$, mean circulating concentrations were $0.3 \pm 0.1 \mathrm{ng} / \mathrm{mL}$ and did not differ for the SR and D25R treatments for all cows combined $(P=0.28)$, CL cows $(P=0.14)$, and NoCL $(P=0.58)$ cows (Table 2$)$. The proportion of cows with $\mathrm{P} 4>0.5 \mathrm{ng} / \mathrm{mL}$ also did not differ for the SR and the D25R treatment for all cows combined $(P=0.52)$, CL cows $(P=0.35)$, and NoCL $(P=0.88)$ cows (Table 2$)$. Parity did not affect the proportion of cows with $\mathrm{P} 4>0.5 \mathrm{ng} / \mathrm{mL}$ for any of the groups $(P>0.10)$. Luteal regression risk using a $0.5 \mathrm{ng} / \mathrm{mL} \mathrm{P} 4$ cutoff did not differ $(P=0.11)$ for cows with a CL at NPD in the SR $(95.5 \% ; 90.9$ to 97.9$)$ and D25R $(91.2 \%$; 86.5 to 94.4$)$ treatment and did not differ $(P=0.33)$ for primiparous $(92.4 \% ; 87.3$ to 95.6$)$ and multiparous $(94.8 \% ; 90.5$ to 97.2$)$ cows.

For all cows combined, the diameter of the largest follicle present on the ovaries at NPD (i.e., including all follicles visualized by TUS regardless of size) was greater $(P=0.03$; Table 3$)$ for the $\mathrm{SR}$ than for the D25R treatment and was greater $(P=0.04)$ for multiparous $(17.4 \pm 0.4 \mathrm{~mm})$ than for primiparous cows $(16.3 \pm 0.4 \mathrm{~mm})$. When putative follicular cysts (i.e., fluid-filled cavities $>25 \mathrm{~mm}$ in diameter with follicular appearance) were removed from the analysis, follicle size differed by treatment $(P<0.01$; Table 3$)$ because cows in SR had larger follicles than cows in D25R, whereas multiparous cows $(15.7 \pm 0.3 \mathrm{~mm})$ tended $(P$ $=0.06)$ to have larger follicles than primiparous cows $(15.0 \pm 0.3 \mathrm{~mm})$. For CL cows only, the largest follicle diameter including all follicles (i.e., no size restriction) did not differ $(P=0.63$; Table 3$)$ for the SR and D25R treatments but differed by parity $(P=0.04)$ because multiparous cows $(16.5 \pm 0.4 \mathrm{~mm})$ had larger follicles than primiparous cows $(15.5 \pm 0.3 \mathrm{~mm})$. Conversely, after removing putative follicular cysts, follicle size differed $(P=0.04$; Table 3$)$ because cows in SR had larger follicles than cows in D25R, and multiparous cows (15.6 $\pm 0.2 \mathrm{~mm})$ had larger $(P=0.04)$ follicles than primiparous cows $(14.9 \pm 0.2 \mathrm{~mm})$. For NoCL cows, the largest follicle diameter including all follicles (i.e., no size restriction) did not differ $(P=0.13$; Table3) for
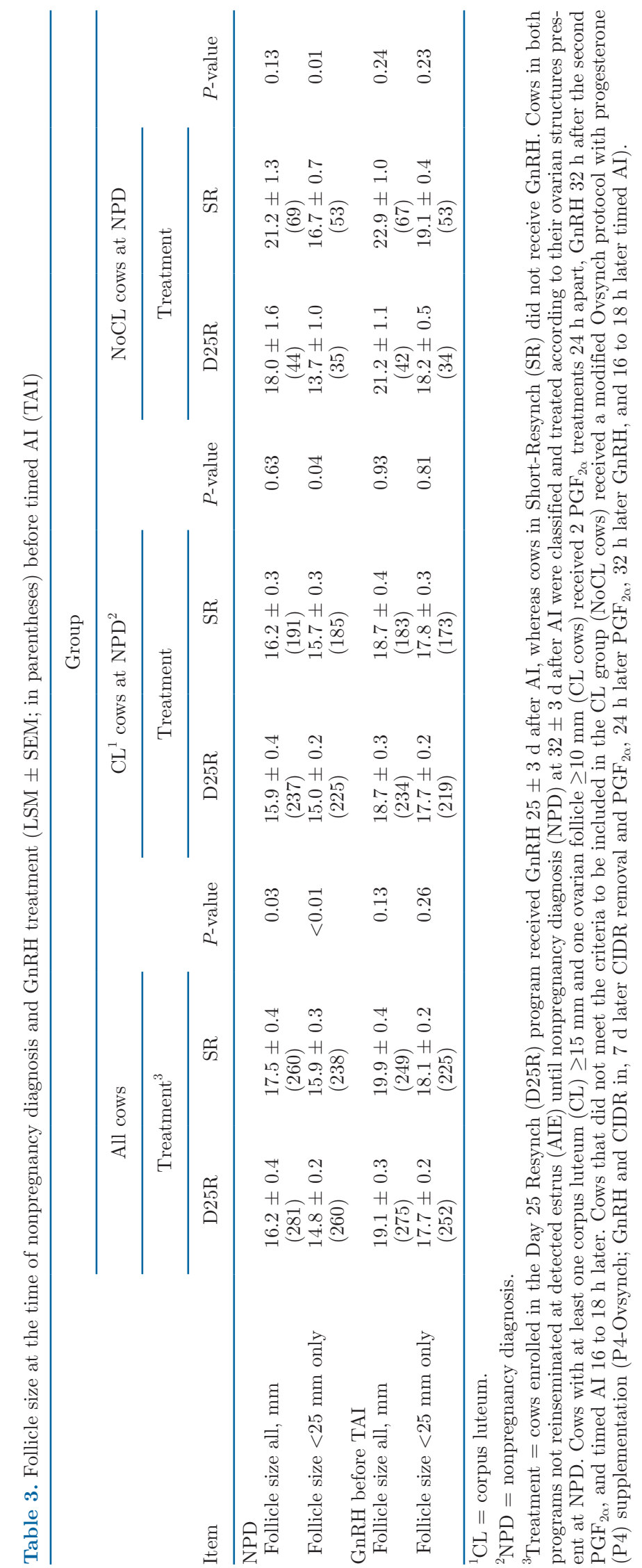
the SR and D25R treatments and did not differ by parity $(P=0.23)$. Conversely, after removing putative follicular cysts, follicle size differed $(P=0.01)$ because cows in SR had larger follicles than cows in the D25R treatment. Parity did not affect follicle size $(P=0.72)$.

At the time of the GnRH before TAI, the diameter of the largest follicle visualized by TUS (no size restriction) for all cows did not differ by treatment $(P=0.13$; Table 3) but tended to be greater $(P=0.08)$ for multiparous $(19.9 \pm 0.4 \mathrm{~mm})$ than primiparous cows $(19.0$ $\pm 0.4 \mathrm{~mm})$. After removing putative follicular cysts, neither treatment $(P=0.26$; Table 3$)$ nor parity $(P=$ 0.12 ) affected follicle size. For CL cows, the largest follicle diameter did not differ $(P=0.93)$ for cows in SR and D25R but was greater $(P=0.02)$ for multiparous $(19.3 \pm 0.4 \mathrm{~mm})$ than primiparous cows $(18.1 \pm 0.3$ $\mathrm{mm}$ ). Similarly, after removing putative cysts, follicle size did not differ by treatment $(P=0.80)$ or parity $(P$ $=0.11$ ). For NoCL cows, the largest follicle diameter did not differ $(P=0.24)$ for the SR and D25R treatments or parity $(P=0.58)$. Similarly, after removing putative follicular cysts, neither treatment $(P=0.23)$ nor parity affected follicle size $(P=0.63)$.

\section{DISCUSSION}

In support of our hypothesis, implementation of the SR and D25R programs for management of second and greater AI services of lactating dairy cows resulted in similar time to pregnancy and proportion of nonpregnant cows for up to $210 \mathrm{~d}$ after first service. The similar performance of cows in both programs was due to compensation between pregnancies generated by AI at detected estrus before NPD for SR and pregnancies from TAI services after NPD for D25R. The SR program benefited from the greater proportion of cows detected in estrus (+10 percentage points) because they were reinseminated earlier and their $\mathrm{P} / \mathrm{AI}$ was similar to that of TAI services for the same group. Insemination of more cows at detected estrus before NPD was expected because removing the $\mathrm{GnRH}$ treatment before NPD in the SR program was meant to avoid interfering with expression of estrous behavior in some cows, favoring AIE rather than TAI. Notably, the proportion of cows AIE before NPD for SR was in the range previously reported in 2 experiments using the same program (Wijma et al., 2017, 2018). The statistically significant but numerically small (i.e., $<3$ percentage points) reduction in $\mathrm{P} / \mathrm{AI}$ for cows $\mathrm{AIE}$ in $\mathrm{SR}$ compared with D25R was unexpected but could be explained, at least in part, by the different fertility potential of cows AIE in each treatment. On the other hand, the reduction in the proportion of cows detected in estrus for the D25R treatment was expected because suppression of estrus in some cows is a consequence of $\mathrm{GnRH}$ treatments to induce ovulation and initiate a new follicular wave as part of resynchronization protocols initiated $<30 \mathrm{~d}$ after AI (Chebel et al., 2003; Bruno et al., 2014; Wijma et al., 2017). The magnitude of this reduction varied depending on the interval after $\mathrm{AI}$ at which the $\mathrm{GnRH}$ treatment was administered, with more estrus suppression observed when GnRH was given closer to 20 than 30 d after AI (Chebel et al., 2003; Bruno et al., 2014; Wijma et al., 2017). Of note, the reduction in proportion of cows detected in estrus after $\mathrm{GnRH}$ given at 25 $\pm 3 \mathrm{~d}$ after $\mathrm{AI}$ in previous experiments was $\sim 10$ percentage points (Bruno et al., 2014; Wijma et al., 2017). Thus, for the D25R program, the GnRH treatment at $25 \pm 3$ d after AI was expected to suppress expression of behavioral estrus in some cows, favoring submission to TAI rather than AIE. In particular, because at the time of $\mathrm{GnRH}$ treatment, approximately half of the cows had circulating concentrations of $\mathrm{P} 4$ (i.e., $<1 \mathrm{ng} /$ $\mathrm{mL}$ ) known to favor GnRH-induced LH release (Giordano et al., 2012a; Stevenson and Pulley, 2016) and most likely had a preovulatory follicle responsive to a GnRH-induced LH surge as observed in other studies (Wijma et al., 2016, 2017).

The observed differences in $\mathrm{P} / \mathrm{AI}$ between treatments for CL cows supported the hypothesis that GnRH treatment $7 \mathrm{~d}$ before NPD would increase the fertility of TAI services. This was critical to the success of the D25R program because the $\sim 10$-percentage-point gain in $\mathrm{P} / \mathrm{AI}$ for $\mathrm{CL}$ cows generated enough pregnancies to compensate for those not generated by AIE before NPD. In Ovsynch-like protocols, induction of ovulation with GnRH is meant to control the initiation of a new follicular wave from which an ovulatory follicle is generated (Pursley et al., 1995; Vasconcelos et al., 1999). Ovulation also results in formation of a new CL that supplies P4 during ovulatory follicle development (Pursley et al., 1995; Vasconcelos et al., 1999). Thus, beyond the expected effect of GnRH treatment on the reinsemination pattern, we hypothesized that $\mathrm{GnRH}$ would increase the proportion of cows with a CL and reduce follicle size at the time of induction of luteolysis. Both hypotheses were supported because more cows had a CL $\geq 15 \mathrm{~mm}$ and a follicle $\geq 10 \mathrm{~mm}$, circulating concentrations of $\mathrm{P} 4$ were greater, and follicle size was reduced (excluding putative cysts) for cows in the D25R treatment compared with the SR treatment at NPD. Formation of a new CL after GnRH likely helped increase P/AI by improving the hormonal milieu before TAI. High circulating concentrations of P4 before induction of luteolysis in synchronization of ovulation protocols increased $\mathrm{P} / \mathrm{AI}$ of TAI services through improved synchrony of ovulation and embryo quality (Rivera et al., 2011; Giordano et al., 2012b; Bisinotto 
et al., 2015). In our experiment, such an effect could have been more pronounced in cows that had a CL present and ovulated in response to GnRH as they had more than one active CL and thereby greater circulating concentrations of $\mathrm{P} 4$ during follicle growth.

Moreover, the most likely reason for reduced follicle size at NPD for cows in D25R was fewer days of follicle growth and less variation for timing of follicular wave initiation in cows that ovulated in response to GnRH (Wijma et al., 2017). This is relevant because better control of the follicular wave dynamics before TAI leads to greater fertility (Bello et al., 2006; Galvão and Santos, 2010; Wijma et al., 2017). Interestingly, follicle size was no longer different for CL cows at the time of the GnRH before TAI. This can be explained by either a slightly greater follicle growth rate after NPD for CL cows in D25R or lesser follicle growth rate for CL cows in SR. The latter is most likely because in a similar experiment in which follicle growth was monitored, the ovulatory follicle for CL cows in the SR program reached $10 \mathrm{~mm}$ in diameter $1.8 \mathrm{~d}$ earlier than the ovulatory follicle of CL cows in D25R (Wijma et al., 2017). The lack of difference for P4 outcomes at the time of the GnRH treatment before TAI and luteal regression risks for CL cows further supported a central role of better control of follicular wave dynamics and improved hormonal milieu before TAI on the greater fertility of CL cows in D25R.

Another possible contributing factor to the difference in $\mathrm{P} / \mathrm{AI}$ for $\mathrm{CL}$ cows may simply have been the shift in the population of cows that received TAI. More cows reinseminated at detected estrus for SR may have resulted in an overrepresentation of cows with reduced reproductive potential among those that received TAI (i.e., cows with greater reproductive potential were AIE before NPD). Conversely, for D25R, more cows with greater fertility potential may have been represented in the group that received TAI. This is because some of the cows that ovulated in response to $\mathrm{GnRH}$ could have been AIE before NPD if the GnRH was not included. It is also plausible to speculate that some cows that received TAI could have had relatively similar P/ $\mathrm{AI}$ if reinseminated at detected estrus. The latter may be as relevant as maximizing the proportion of cows AIE because the full benefits of earlier insemination at detected estrus may not be realized if fertility is poor. If that were the case, the lesser expected P/AI of CL cows that receive SR may not be fully compensated, resulting in delayed pregnancy and more cows not pregnant at the end of the insemination period. Thus, maximizing both the proportion of cows AIE before NPD and the $\mathrm{P} / \mathrm{AI}$ of these AI services is critical for optimal reproductive performance with the SR program. In this regard, our data indicated that it is possible to achieve similar performance with the SR and the D25R protocol when $\sim 60 \%$ of the cows receive AIE before NPD and their $\mathrm{P} / \mathrm{AI}$ is in the range of $38 \%$.

A key aspect of the programs compared in this experiment was the synergistic effect of the protocols used for CL and NoCL cows. Assigning cows to TAI protocols depending on the type and size of ovarian structures present at NPD has been used as a tool to optimize the reproductive performance of dairy cows (Bartolome et al., 2005; Giordano et al., 2016; Wijma et al., 2018). In this case, cows eligible for the CL group received a treatment aimed primarily at minimizing the reinsemination interval. Conversely, cows in the NoCL group received the P4-Ovsynch protocol with 2 $\mathrm{PGF}_{2 \alpha}$ treatments because the protocol used for CL cows would have likely compromised their fertility to an extent that could have completely offset the benefit of earlier reinsemination. In addition, the protocol used for NoCL cows was aimed at increasing their fertility, as demonstrated in previous studies that compared this protocol with the Ovsynch-56 protocol with no $\mathrm{P} 4$ supplementation and a single PGF treatment (Wijma et al., 2018).

Similar P/AI for NoCL cows in spite of the GnRH treatment before NPD in D25R was expected. Lack of a CL $\geq 15 \mathrm{~mm}$, a follicle $\geq 10 \mathrm{~mm}$, or both at NPD indicated lack of ovulation in response to $\mathrm{GnRH}$, which would prevent any benefit from the treatment. Reduced GnRH-induced LH release due to the presence of a functional CL (Giordano et al., 2012a; Stevenson and Pulley, 2016), absence of a follicle responsive to an LH surge (Vasconcelos et al., 1999; Galvão and Santos, 2010), or both are common reasons for lack of ovulation in response to GnRH. Some cows may also have experienced luteolysis from the time of $\mathrm{GnRH}$ treatment until NPD. All of these issues have been previously reported for cows in the NoCL group managed with the D25R program (Wijma et al., 2017). Indeed, P4 data for NoCL cows at $25 \pm 3 \mathrm{~d}$ after AI suggested that a subgroup of cows had concentrations of P4 associated with reduced ovulation risk in response to $\mathrm{GnRH}$ (i.e., $\geq 1 \mathrm{ng} / \mathrm{mL}$ ) and that luteolysis occurred from the time of GnRH to NPD for some cows. The differences for follicle size at NPD for NoCL cows suggested that follicular wave dynamics might have been altered by the GnRH treatment through mechanisms independent of ovulation or simply due to the shift in the population of cows that reached NPD. Regardless of the cause, the implications were likely minimal given the similar P4 and follicle size outcomes observed at the time of the GnRH before TAI, and the similar P/AI of cows in both treatments. The apparent similar response to the protocol was not surprising because the endocrine conditions (i.e., $<1 \mathrm{ng} / \mathrm{mL}$ of $\mathrm{P} 4$ in most cows) and 
ovarian structures (i.e., follicle $>10 \mathrm{~mm}$ in most cows) present at NPD were favorable for a good response to the P4-Ovsynch protocol. In agreement, similar P/AI for NoCL cows in D25R and SR were reported in a previous experiment (Wijma et al., 2017).

Proper identification and measurement of ovarian structures is important for the success of reproductive management strategies based on targeted management of cows with different types and sizes of ovarian structures. Unfortunately, some level of error is expected when B-mode TUS is used to classify cows based on ovarian structures (Silva et al., 2007; Stevenson et al., 2008; Mendonça et al., 2019). Human error, technical difficulties caused by dynamic physiological and structural changes of CL and follicles (Siqueira et al., 2009), and the presence of putative follicular or luteal cysts may all contribute to inaccurate assignment of cows to CL and NoCL groups (Bartolome et al., 2005; Giordano et al., 2016; Mendonça et al., 2019). For example, the $\sim 10 \%$ and $18 \%$ of cows in the CL group with P4 $<1 \mathrm{ng} /$ $\mathrm{mL}$ in the $\mathrm{D} 25 \mathrm{R}$ and $\mathrm{SR}$ treatments, respectively, can be explained either by the presence of a regressing or fully regressed CL with enough echogenicity to appear physiologically active to technicians or the presence of a $\mathrm{CL} \geq 15 \mathrm{~mm}$ generated after a recent ovulation. The former is known to occur due to the time lag between physiological and structural luteolysis (Siqueira et al., 2009). The latter is possible when a CL formed after a recent ovulation is visualized at NPD. Thus, some cows may have had a CL $\geq 15 \mathrm{~mm}$ that was not yet producing enough $\mathrm{P} 4$ to elevate circulating concentrations to $>1 \mathrm{ng} / \mathrm{mL}$. In this regard, the greater proportion of CL cows with $\mathrm{P} 4<1 \mathrm{ng} / \mathrm{mL}$ in $\mathrm{SR}$ was expected because cows in this treatment can ovulate at random before NPD. In contrast, cows in D25R most likely ovulated either before or in response to the $\mathrm{GnRH}$ treatment before NPD. On the other hand, for the NoCL group, the presence of some cows with $\mathrm{P} 4 \geq 1 \mathrm{ng} / \mathrm{mL}$ at NPD may have been due to a CL $<15 \mathrm{~mm}$ formed after a recent ovulation but capable of maintaining $\mathrm{P} 4$ levels $>1 \mathrm{ng} / \mathrm{mL}$. Another possibility is that some cows had a follicular cyst producing sufficient $\mathrm{P} 4$ to maintain $\mathrm{P} 4$ levels of $>1 \mathrm{ng} / \mathrm{mL}$ (Leslie and Bosu, 1983; Bartolome et al., 2005). Both of these conditions have previously been observed and reported for resynchronized cows (Bartolome et al., 2005; Giordano et al., 2016; Wijma et al., 2017). Further research is warranted to quantify the implications of misclassifying cows in the CL or NoCL group when using the programs compared in this experiment or similar.

Selecting a reproductive management strategy for a particular dairy farm depends upon multiple factors including farm management preferences for use of AIE or TAI, labor resources available, facilities, environmental conditions, herd-specific biological factors, and economics. From a strictly noneconomic perspective, the choice of the SR or D25R for lactating dairy cows may depend primarily on the known or expected success of the farm to reinseminate cows at detected estrus and the $\mathrm{P} / \mathrm{AI}$ of those AI services. Farms that can reinseminate at least 50 to $60 \%$ (ideally more) of cows at detected estrus within $\sim 30 \mathrm{~d}$ of the previous $\mathrm{AI}$ and achieve reasonable P/AI (e.g., 35 to $40 \%$ ) may benefit from the program including the SR protocol for CL cows. In contrast, farms that are less successful at reinseminating cows by AIE may benefit from the D25R program because it leads to good reproductive performance by optimizing the P/AI of TAI services. For some farms, the choice of program may be based primarily on management style preferences. Farms that prefer to maximize AIE services can implement the program including SR, whereas farms that prefer to rely primarily on TAI or prefer to maximize $\mathrm{P} / \mathrm{AI}$ can adopt the program including the D25R protocol for CL cows. Another benefit of the SR compared with the D25R program is the reduction in number of GnRH treatments required, as cows do not receive GnRH $25 \pm 3 \mathrm{~d}$ after AI when their pregnancy status is unknown.

Based on the data available, in all cases, the $\mathrm{P} 4$ Ovsynch protocol used in this and our previous experiments (Wijma et al., 2017, 2018) seems to be a reasonable choice for NoCL cows because it increases $\mathrm{P} / \mathrm{AI}$ compared with the basic Ovsynch protocol (Wijma et al., 2018) without extending the reinsemination interval. For farms that cannot or prefer not to use $\mathrm{P} 4$ supplementation through intravaginal $\mathrm{P} 4$-releasing devices, alternative protocols that increase fertility through presynchronization may increase $\mathrm{P} / \mathrm{AI}$ of NoCL cows (Dewey et al., 2010; Lopes et al., 2013; Giordano et al., 2016).

\section{CONCLUSIONS}

The use of SR and D25R protocols for CL cows in combination with the P4-Ovsynch protocol for NoCL cows (as defined in our experiment) resulted in similar hazard of pregnancy and a similar proportion of nonpregnant cows at $210 \mathrm{~d}$ after first service. Therefore, both reproductive management strategies may be reasonable alternatives to manage lactating dairy cows for second and greater AI services. Farms that are or expect to be successful with reinsemination of cows at detected estrus may use the program including SR to reduce unnecessary treatment with $\mathrm{GnRH}$ before NPD to pregnant cows, the number of cows to conduct pregnancy testing, and the use of TAI after NPD. In contrast, the program including D25R may be the choice for farms that prefer to optimize repro- 
ductive performance by maximizing $\mathrm{P} / \mathrm{AI}$ with TAI or for farms that are less successful at detecting cows in estrus after a previous insemination. We also concluded that the GnRH treatment at $25 \pm 3 \mathrm{~d}$ after AI for cows in the D25R program was responsible for the differences in the reinsemination pattern and physiological outcomes monitored at and immediately after NPD.

\section{ACKNOWLEDGMENTS}

We extend our gratitude to the owners and personnel from the two commercial farms that participated of our experiment for access to their cows and facilities and their continuous support of this research. We also extend our gratitude to Merck Animal Health (Summit, NJ) for providing the $\mathrm{GnRH}$ and $\mathrm{PGF}_{2 \alpha}$ products and Zoetis (Florham Park, NJ) for providing the CIDR devices used for the experiment. This material is based upon work supported by the New York Farm Viability Institute through grant FVI 17-013 to JOG and the USDA National Institute of Food and Agriculture (Washington, DC) Hatch under 1007421 and Multistate 100572 to JOG. Any opinions, findings, conclusions, or recommendations expressed in this publication are those of the authors and do not necessarily reflect the view of the National Institute of Food and Agriculture (NIFA) or the United States Department of Agriculture (USDA). The authors have not stated any conflicts of interest.

\section{REFERENCES}

Abramson, J. H. 2011. WINPEPI updated: Computer programs for epidemiologists, and their teaching potential. Epidemiol. Perspect. Innov. 8:1.

Bartolome, J. A., A. Sozzi, J. McHale, P. Melendez, A. C. Arteche, F. T. Silvestre, D. Kelbert, K. Swift, L. F. Archbald, and W. W. Thatcher. 2005. Resynchronization of ovulation and timed insemination in lactating dairy cows, II: assigning protocols according to stages of the estrous cycle, or presence of ovarian cysts or anestrus. Theriogenology 63:1628-1642. https://doi.org/10.1016/j .theriogenology.2004.07.017.

Bello, N. M., J. P. Steibel, and J. R. Pursley. 2006. Optimizing ovulation to first $\mathrm{GnRH}$ improved outcomes to each hormonal injection of Ovsynch in lactating dairy cows. J. Dairy Sci. 89:3413-3424. https://doi.org/10.3168/jds.S0022-0302(06)72378-5.

Bilby, T. R., R. G. S. Bruno, K. J. Lager, R. C. Chebel, J. G. N. Moraes, P. M. Fricke, G. Lopes Jr., J. O. Giordano, J. E. P. Santos, F. S. Lima, J. S. Stevenson, and S. L. Pulley. 2013. Supplemental progesterone and timing of resynchronization on pregnancy outcomes in lactating dairy cows. J. Dairy Sci. 96:7032-7042. https:/ /doi.org/10.3168/jds.2013-6960.

Bisinotto, R. S., L. O. Castro, M. B. Pansani, C. D. Narciso, N. Martinez, L. D. Sinedino, T. L. Pinto, N. S. Van de Burgwal, H. M. Bosman, R. S. Surjus, W. W. Thatcher, and J. E. Santos. 2015. Progesterone supplementation to lactating dairy cows without a corpus luteum at initiation of the Ovsynch protocol. J. Dairy Sci. 98:2515-2528. https://doi.org/10.3168/jds.2014-9058.

Bruno, R. G., J. G. Moraes, J. A. Hernandez-Rivera, K. J. Lager, P. R. Silva, A. L. Scanavez, L. G. Mendonca, R. C. Chebel, and T. R. Bilby. 2014. Effect of an Ovsynch56 protocol initiated at different intervals after insemination with or without a presynchronizing injection of gonadotropin-releasing hormone on fertility in lactating dairy cows. J. Dairy Sci. 97:185-194. https://doi.org/10.3168/ jds.2013-6827.

Chebel, R. C., J. E. Santos, R. L. Cerri, K. N. Galvao, S. O. Juchem, and W. W. Thatcher. 2003. Effect of resynchronization with GnRH on day 21 after artificial insemination on pregnancy rate and pregnancy loss in lactating dairy cows. Theriogenology 60:1389-1399. https://doi.org/10.1016/S0093-691X(03)00117-1.

Dewey, S. T., L. G. Mendonca, G. Lopes Jr., F. A. Rivera, F. Guagnini, R. C. Chebel, and T. R. Bilby. 2010. Resynchronization strategies to improve fertility in lactating dairy cows utilizing a presynchronization injection of GnRH or supplemental progesterone: I. Pregnancy rates and ovarian responses. J. Dairy Sci. 93:4086-4095. https://doi.org/10.3168/jds.2010-3233.

Fricke, P. M., D. Z. Caraviello, K. A. Weigel, and M. L. Welle. 2003. Fertility of dairy cows after resynchronization of ovulation at three intervals following first timed insemination. J. Dairy Sci. 86:39413950. https://doi.org/10.3168/jds.S0022-0302(03)74003-X.

Galvão, K. N., and J. E. Santos. 2010. Factors affecting synchronization and conception rate after the Ovsynch protocol in lactating Holstein cows. Reprod. Domest. Anim. 45:439-446. https://doi .org/10.1111/j.1439-0531.2008.01220.x.

Giordano, J. O., P. M. Fricke, J. N. Guenther, G. Lopes Jr., M. M. Herlihy, A. B. Nascimento, and M. C. Wiltbank. 2012a. Effect of progesterone on magnitude of the luteinizing hormone surge induced by two different doses of gonadotropin-releasing hormone in lactating dairy cows. J. Dairy Sci. 95:3781-3793. https://doi.org/ $10.3168 /$ jds.2011-5155.

Giordano, J. O., M. L. Stangaferro, R. Wijma, W. C. Chandler, and R. D. Watters. 2015. Reproductive performance of dairy cows managed with a program aimed at increasing insemination of cows in estrus based on increased physical activity and fertility of timed artificial inseminations. J. Dairy Sci. 98:2488-2501. https://doi .org/10.3168/jds.2014-8961.

Giordano, J. O., M. J. Thomas, G. Catucuamba, M. D. Curler, M. Masello, M. L. Stangaferro, and R. Wijma. 2016. Reproductive management strategies to improve the fertility of cows with a suboptimal response to resynchronization of ovulation. J. Dairy Sci. 99:2967-2978. https://doi.org/10.3168/jds.2015-10223.

Giordano, J. O., M. C. Wiltbank, J. N. Guenther, R. Pawlisch, S. Bas, A. P. Cunha, and P. M. Fricke. 2012b. Increased fertility in lactating dairy cows resynchronized with Double-Ovsynch compared with Ovsynch initiated $32 \mathrm{~d}$ after timed artificial insemination. J. Dairy Sci. 95:639-653. https://doi.org/10.3168/jds.2011-4418.

Leslie, K. E., and W. T. Bosu. 1983. Plasma progesterone concentrations in dairy cows with cystic ovaries and clinical responses following treatment with fenprostalene. Can. Vet. J. 24:352-356.

Lopes, G. Jr., J. O. Giordano, A. Valenza, M. M. Herlihy, J. N. Guenther, M. C. Wiltbank, and P. M. Fricke. 2013. Effect of timing of initiation of resynchronization and presynchronization with gonadotropin-releasing hormone on fertility of resynchronized inseminations in lactating dairy cows. J. Dairy Sci. 96:3788-3798. https:// doi.org/10.3168/jds.2012-6429.

Mendonça, L. G. D., L. S. Rocha, B. E. Voelz, G. T. Lima, A. L. A. Scanavez, and J. S. Stevenson. 2019. Presynchronization strategy using prostaglandin F2alpha, gonadotropin-releasing hormone, and detection of estrus to improve fertility in a resynchronization program for dairy cows. Theriogenology 124:39-47. https://doi .org/10.1016/j.theriogenology.2018.09.027.

Moreira, F., C. Orlandi, C. A. Risco, R. Mattos, F. Lopes, and W. W. Thatcher. 2001. Effects of presynchronization and bovine somatotropin on pregnancy rates to a timed artificial insemination protocol in lactating dairy cows. J. Dairy Sci. 84:1646-1659. https: //doi.org/10.3168/jds.S0022-0302(01)74600-0.

Pursley, J. R., M. R. Kosorok, and M. C. Wiltbank. 1997. Reproductive management of lactating dairy cows using synchronization of ovulation. J. Dairy Sci. 80:301-306. https://doi.org/10.3168/jds .S0022-0302(97)75938-1.

Pursley, J. R., M. O. Mee, and M. C. Wiltbank. 1995. Synchronization of ovulation in dairy cows using PGF2alpha and GnRH. 
Theriogenology 44:915-923. https://doi.org/10.1016/0093 $-691 \mathrm{X}(95) 00279-\mathrm{H}$

Rivera, F. A., L. G. Mendonca, G. Lopes Jr., J. E. Santos, R. V. Perez, M. Amstalden, A. Correa-Calderon, and R. C. Chebel. 2011. Reduced progesterone concentration during growth of the first follicular wave affects embryo quality but has no effect on embryo survival post transfer in lactating dairy cows. Reproduction 141:333-342. https://doi.org/10.1530/REP-10-0375.

Silva, E., R. A. Sterry, and P. M. Fricke. 2007. Assessment of a practical method for identifying anovular dairy cows synchronized for first postpartum timed artificial insemination. J. Dairy Sci. 90:3255-3262. https://doi.org/10.3168/jds.2006-779.

Siqueira, L. G., C. A. Torres, L. S. Amorim, E. D. Souza, L. S. Camargo, C. A. Fernandes, and J. H. Viana. 2009. Interrelationships among morphology, echotexture, and function of the bovine corpus luteum during the estrous cycle. Anim. Reprod. Sci. 115:18-28. https://doi.org/10.1016/j.anireprosci.2008.11.009.

Souza, A., H. Ayres, R. Ferreira, and M. Wiltbank. 2008. A new presynchronization system (Double-Ovsynch) increases fertility at first postpartum timed AI in lactating dairy cows. Theriogenology 70:208-215.

Sterry, R. A., M. L. Welle, and P. M. Fricke. 2006. Effect of interval from timed artificial insemination to initiation of resynchronization of ovulation on fertility of lactating dairy cows. J. Dairy Sci. 89:2099-2109. https://doi.org/10.3168/jds.S0022-0302(06)72280 -9 .

Stevenson, J. S., and S. L. Pulley. 2016. Feedback effects of estradiol and progesterone on ovulation and fertility of dairy cows after gonadotropin-releasing hormone-induced release of luteinizing hormone. J. Dairy Sci. 99:3003-3015. https://doi.org/10.3168/jds .2015-10091.

Stevenson, J. S., D. E. Tenhouse, R. L. Krisher, G. C. Lamb, J. E. Larson, C. R. Dahlen, J. R. Pursley, N. M. Bello, P. M. Fricke, M. C. Wiltbank, D. J. Brusveen, M. Burkhart, R. S. Youngquist, and H. A. Garverick. 2008. Detection of anovulation by heatmount detectors and transrectal ultrasonography before treatment with progesterone in a timed insemination protocol. J. Dairy Sci. 91:2901-2915. https://doi.org/10.3168/jds.2007-0856.

Tenhagen, B. A., M. Drillich, R. Surholt, and W. Heuwieser. 2004. Comparison of timed AI after synchronized ovulation to AI at estrus: Reproductive and economic considerations. J. Dairy Sci. 87:85-94. https://doi.org/10.3168/jds.S0022-0302(04)73145-8.
Van Amburgh, M. E., E. A. Collao-Saenz, R. J. Higgs, D. A. Ross, E. B. Recktenwald, E. Raffrenato, L. E. Chase, T. R. Overton, J. K. Mills, and A. Foskolos. 2015. The Cornell Net Carbohydrate and Protein System: Updates to the model and evaluation of version 6.5. J. Dairy Sci. 98:6361-6380. https://doi.org/10.3168/jds.2015 -9378 .

Vasconcelos, J. L., R. W. Silcox, G. J. Rosa, J. R. Pursley, and M. C. Wiltbank. 1999. Synchronization rate, size of the ovulatory follicle, and pregnancy rate after synchronization of ovulation beginning on different days of the estrous cycle in lactating dairy cows. Theriogenology 52:1067-1078. https://doi.org/10.1016/S0093 -691X(99)00195-8.

Wijma, R., M. M. Perez, M. Masello, M. L. Stangaferro, and J. O. Giordano. 2018. A resynchronization of ovulation program based on ovarian structures present at nonpregnancy diagnosis reduced time to pregnancy in lactating dairy cows. J. Dairy Sci. 101:16971707. https://doi.org/10.3168/jds.2017-13489.

Wijma, R., M. L. Stangaferro, M. M. Kamat, S. Vasudevan, T. L. Ott, and J. O. Giordano. 2016. Embryo mortality around the period of maintenance of the corpus luteum causes alterations to the ovarian function of lactating dairy cows. Biol. Reprod. 95:112. https://doi .org/10.1095/biolreprod.116.142075.

Wijma, R., M. L. Stangaferro, M. Masello, G. E. Granados, and J. O. Giordano. 2017. Resynchronization of ovulation protocols for dairy cows including or not including gonadotropin-releasing hormone to induce a new follicular wave: Effects on re-insemination pattern, ovarian responses, and pregnancy outcomes. J. Dairy Sci. 100:7613-7625. https://doi.org/10.3168/jds.2017-12550.

\section{ORCIDS}

M. M. Pérez @ https://orcid.org/0000-0002-9626-8735

R. Wijma ๑ https://orcid.org/0000-0003-4917-1604

M. Scarbolo @ \ttps://orcid.org/0000-0002-6911-2380

E. Cabrera ๑ https://orcid.org/0000-0002-4738-5353

F. Sosa @ https://orcid.org/0000-0003-2768-1881

E. M. Sitko @ https://orcid.org/0000-0001-6530-9955

J. O. Giordano @ https://orcid.org/0000-0003-1455-6811 